\title{
What A Difference A Day Makes - On the Common Market Microstructure of Trading Days
}

\author{
Frank Gerhard ${ }^{a, b}$, Dieter Hess ${ }^{a, c}$ and Winfried Pohlmeier ${ }^{a, b}$ \\ ${ }^{a}$ Center of Finance and Econometrics, \\ ${ }^{b}$ University of Konstanz, Germany \\ ${ }^{c}$ Stern School of Business, New York, N.Y. \\ email: frank.gerhard@uni-konstanz.de, \\ dhess@stern.nyu.edu,winfried.pohlmeier@uni-konstanz.de
}

November 1998

\begin{abstract}
This paper analyzes the issue of interday stability of the price process using transaction data. While the vast majority of empirical studies on the micostructure of financial markets based on high frequency data rests on the tacit assumption that observed prices are generated by a unique price process, implying the existence of a common set of parameters driving this process, we question this assumption by means of a minimum distance estimation framework. Starting from estimates specific for each day's price process, the proposed procedure enables us to work out a common structure accross trading days and allows us to disentangle the pecularities of trading days which are marked by certain news events.

The power of the methodology is demonstrated by analyzing the determinants of transaction price changes for the BUND future trading at the LIFFE on the basis of 22 subsequent trading days. Using the ordered probit model in the fist stage of estimation we account for the discreteness of the price changes as well as the fact that price changes occur at irregular intervals. Our empirical findings confirm that to a large extent trading days do share share a common structure. However, single event dominated days are likely to render parameter estimates inconsistent. These event dominated days share no common features with respect to the price process. Theoretical reasoning of literature on market microstructures supporting the existence of local deviations from the martingale hypothesis can be confirmed.
\end{abstract}

JEL classification: C22, C25, G14 
Acknowlegdements: For valuable comments we would like to thank Michel Dacorogna, Günther Franke, Joel Hasbrouck, Frank de Jong, Matthias Külpmann, Jeffrey Russel, and Werner Smolny. Earlier versions of this paper have been presented at the meeting of the European Economic Association in Tolouse, the HFDF-II conference in Zurich, and the German Finance Association in Mannheim, as well as in seminars at the universities of Konstanz, Mannheim, Nuremberg, and Tübingen. The authors would like to thank the Deutsche Forschungsgemeinschaft and the BMW AG for financial support. Reuters money market headlines were kindly provided by Olsen \& Associates, Zurich. Intraday data of Bund futures trading were obtained from LIFFE, London. All remaining errors are our sole responsibility. 


\section{Introduction}

In the empirical analysis of market microstructure virtually all models include a tacit assumption on the stability of the underlying information diffusion process. ${ }^{1}$ This is not only valid for structural models ${ }^{2}$, but also holds for reduced form approaches ${ }^{3}$. However, extraordinary events occuring on only a few individual trading days might blur the overall picture of a particular market place which describes the trading mechanism well for the majority of trading days. Increasing the sample size may reduce the weight of extraordinary events not explicitly accounted for, generating a contaminated picture of typical trading days. Such a procedure ignores the information contained in these singular events and even worse, it prohibits a careful analysis of singularities, i.e. major news releases, adjustments of key interest rates, crashes etc., which are a focal point of interest for practitioneers and the public. Finally, the systematic analysis of those events might also generate valuable insights into the functioning of financial markets. The aforementioned procedure of extending the sample crucially relies on the assumption that (i) the proportion of events unexplained by the model diminishes when the sample is expanded and that (ii) the trading process is not subject to an ongoing change, e.g. a shift of volume from one trading place to another or from one asset to another.

\footnotetext{
${ }^{1}$ See Goodhart and O'Hara (1997) for a recent survey on theoretical and empirical work.

${ }^{2}$ E.g. Hasbrouck (1991), Easley, Kiefer, O’Hara, and Paperman (1996), Easley, Kiefer, and O'Hara (1997), or Ait-Sahalia (1998).

${ }^{3}$ E.g. Hausman, Lo, and MacKinlay (1992), Bollerslev and Domowitz (1993), Russell and Engle (1998), or Andersen and Bollerslev (1998).
} 
Of course, the point is well taken that it is hard to assess the stability of empirical relationships in a manner which is satisfactory to economic theorists. The mere fact that a subset of observations is not described well by a certain empirical specification is utterly uninformative. Major questions remain to be answered.

- In what respect do these observations differ from others in the sample?

- What might cause the shift in information processing?

- Which dimensions of the price process are affected?

In this paper we exploit the richness of time series of intraday data to assess the problem of a common market microstructure over longer time horizons. Thereby, a single trading day serves as a natural entity which in liquid markets contains sufficient observations at the transaction level to estimate even demanding nonlinear models of the price process. In particular, our analysis of the price process at the transaction level is based on the ordered probit model with conditional heteroskedasticity as it was first suggested by Hausman, Lo, and MacKinlay (1992) and subsequently applied by Bollerslev and Melvin (1994) to the analysis of quotes. The necessity to apply quantal response models to map the price process of transactions relies on two intrinsic features of transaction data. First, prices are quoted in discrete units ${ }^{4}$ (ticks) and second, the speed of the price adjustment

\footnotetext{
${ }^{4}$ This fact is treated here as an econometric problem, see e.g. Harris (1994) for an analysis of the effects of tick size on financial markets' efficiency, especially on transaction costs and traded volume.
} 
process, i.e. the time between transactions, is clearly irregular and might well be described by duration models, see Engle (1996), Engle and Russell (1997), and Russell and Engle (1998). The ordered probit is capable of mapping the structure of serial dependence in the data, and yet, remains managable from a computational point of view. The inclusion of conditioning information is straightforward in order to account for factors assumed to drive the price process. This is a substantial advantage compared to the rounding models of Ball (1988), Cho and Frees (1988), or Harris (1990). Last but not least, this methodology avoids an aggregation of transactions and preserves a maximum amount of information contained in the data. Easley, Kiefer, and O'Hara (1997) give some empirical evidence on this aggregation problem and argue that the aggregation effect is particularly severe when the information diffusion process is analyzed. In particular, the speed of the price adjusment remains observable in our specification. This is regarded as a crucial information in market microstructure models in the spirit of Easley and O'Hara (1992).

Our research strategy is to start with a very general set-up assuming that each trading day in the sample is a unique event. In subsequent estimation stages we try to find a common structure across trading days. This allows us to account for potential distortions in the price process while imposing as much structure on the price process as standard statistical criteria allow. Therefore, our strategy circumvents the problems of simple pooling approaches, which more or less ignore distortions in the price process. It is also superior to intraday approaches which face the danger of generalizing empirical findings that may only hold for specific trading days. 
The novel feature of this paper is to apply minimum distance estimation in a second estimation stage in order to obtain aggregate estimates for the whole sample period. Kodde, Palm, and Pfann (1990) show that the minimum distance method based on first stage maximum likelihood estimates is asymptotically equivalent to a one stage full information maximum likelihood estimator. However, minimum distance reveals obvious advantages for applied researchers because it yields a testing procedure that starts from the most general specification and tests downwards to the specific model avoiding the estimation of different specifications on the overall sample. The ability to discriminate between different types of trading days may prove to be useful in getting a better understanding of the functioning of financial markets. Although we demonstrate the use of the minimum distance procedure in the context of ordered probit models it is straightforward to apply this methodology to the estimation results of other first step estimators, e.g. ARCH type models. As a practical byproduct the minimum distance approach allows us to circumvent problems that arise from modelling the specific features of the price process at opening and closing hours as well as of overnight price changes.

Our approach differs somewhat from pooled regression methods which usually control only for a few daily peculiarities. Recent econometric approaches by Andersen and Bollerslev (1997a), Andersen, Bollerslev, and Das (1998), and Andersen and Bollerslev (1998) allow the inclusion of scheduled events. They pay tribute to the fact that the well known seasonalities ${ }^{5}$ caused by the opening and closing of the market itself, other related markets,

\footnotetext{
${ }^{5}$ See e.g. Wood, McInish, and Ord (1985) and McInish and Wood (1992) for an analysis of season-
} 
and the effect of lunch hours are distorted by expected, i.e. scheduled announcements which are released on a regular basis. Yet, there is still no generally accepted procedure to resolve the effect of unexpected news releases in the sample. ${ }^{6}$ The same is true for the effects of market expectations around scheduled news events. These advanced refinements, however, rely on the tacit assumption that the effect of a particular news event, e.g. a FOMC meeting without a change in interest rates, is always of the same size independent of the expectations formed by market participants. Hence, they implicitely assume that these effects can be simply captured by dummy variables, and ignore interaction effects implying a shift in the marginal effects of the explanatory variables.

We demonstrate the potential of the methodology introduced here by applying it to the analysis of transaction prices of the Bund future traded at LIFFE in London. The data provides us with information on the prices, associated quotes and proxies for volume. Through the time stamps, we are able to compute the time between transactions. As a complementary data source we use the Reuter's AAMM news headlines to gain additional information on the timing of news items. We choose a sample of 22 trading days which alities of trading at the NYSE, or Dacorogna, Müller, Nagler, Olsen, and Pictet (1993) and Guillaume, Dacorogna, Dave, Müller, Olsen, and Pictet (1997) for the foreign exchange market, or Andersen and Bollerslev (1997b) for an in depth analysis of intraday periodicity.

${ }^{6}$ For a detailed analysis of potential economic implications of expected and unexpected news see Kim and Verrechia (1991). An analysis of unobserved earnings surprises is undertaken by Maddala and Nimalendran (1995) in the context of classical panels using price changes, volume, and bid-ask spread information. 
appears to be small enough to clarify the properties of our modelling procedure in a case study like fashion, but is suffiently large to incorporate some major news events. We use scheduled news releases, such as U.S. employment figures ${ }^{7}$ as well as news which have no clear-cut announcement schedule, such as the adjustment of key interest rates by the German Bundesbank.

For the Bund future trading we are able to work out a common structure across trading days and to disentangle the pecularities of event dominated trading days. Despite the large sample size of around 1.7 thousand transactions per trading day that usually gives rise to the rejection of any null hypothesis on the equality of regression coefficients we do find a common structure for 18 out of 22 trading days. We can show that event dominated trading days are marked by different price processes that share no common structure and render simple pooling estimates inconsistent.

The outline of the paper is as follows. In section 2 we describe our econometric approach. Section 3 contains relevant information on the data and the institutional arrangements. It also provides casual evidence on the presence of a common market microstructure based on intraday estimates. The model specification and the empirical findings are discussed in section 4, while the final section concludes and presents an outlook for future research.

\footnotetext{
${ }^{7}$ See Jones, Lamont, and Lumsdaine (1998) for an analysis of the effect of unemployment figures and producer price index announcements on daily T-bond prices and the references given therein for additional work on the effects of scheduled announcements.
} 


\section{The Estimation Procedure}

The estimation procedure we propose consists of two estimation stages. In the first stage, the observations of the different trading days are treated as separate samples. For each trading day, parameter estimates are obtained by an estimator that is required to be consistent and asymptotically normally distributed. Although focussing on the estimation of discrete price movements, the scope of our approach is much broader since it can be applied to a wider range of estimation methods usually applied to high frequency data. For each day of a sample of $\mathrm{D}$ trading days an auxiliary parameter vector $\lambda_{d}, d=1, \ldots, D$, has to be estimated in the first stage. In the second stage the minimum distance estimation technique is applied. Loosely speaking, this estimation principle chooses the parameters of interest (structural form parameters) which are common to all trading days such that a weighted quadratic distance between the auxiliary parameters (the D intraday parameter vectors) and the structural form parameters is minimized. Hence our approach uses the overall information in the sample by combining the intraday estimates optimally rather than requiring estimation on the pooled sample. Apart from the most obvious advantage of having a clear indication at hand, whether a pooled regresion is valid, or whether one realizes a significant loss of information in the pooling process, this procedure has important practical merits if computationally burdensome estimators are to be applied. Moreover, given the intraday estimates of the first stage a variety of model specifications can be estimated by performing the computationally less demanding minimum distance 
step only. One might think of the pooled regression as a particular form of restricted regression which assumes the constancy of all parameters over all trading days, since Kodde, Palm, and Pfann (1990) have shown that the minimum distance estimates are asymptotically equivalent to the corresponding maximum likelihood esimates based on the entire sample.

\subsection{Econometric Modeling of Discrete Price Changes}

In the first stage of estimation we use the ordered probit model with conditional heteroskedasticity to estimate the determinants of price movements between transactions. This approach which was originally proposed by Hausman, Lo and MacKinlay (1992) is capable of capturing two major features of transaction price changes. First, unlike more conventional approaches to high frequency data based on equally distant time intervals and requiring some aggregation, the ordered probit model operates on the transaction data level. Thus the time between transactions can be included as a covariate to capture the presence of new information in the market. Second, the approach takes into account that price movements at the transaction level are discrete, i.e. reported prices are integer multiples of some divisor called a tick, and take on only a limited number of discrete values.

Define for a trading day $d$ the price change from transaction $t-1$ to transaction $t$ by $Y_{t d}=P_{t+1, d}-P_{t d}$, where $P_{t d}$ is the price at which transaction $t$ was quoted. Here the 
index $t=1, \ldots, T$ denotes the $t$-th transaction and is not directly related to clock time since transactions occur at irregular time intervals. Moreover, define a continuous latent counterpart to the observable discrete price change by $Y_{t}^{*}$. This variable can be regarded as the price pressure or the change in the market expectations in the fundamental value of the asset. The movement of the latent price pressure variable is described by the following heteroscedastic regression model:

$$
\begin{aligned}
& y_{t d}^{*}=X_{t d}^{\prime} \beta_{d}+\epsilon_{t d}, \quad t=1, \ldots, T_{d}, \quad d=1, \ldots, D \\
& \text { with } \quad \mathrm{E}\left[\epsilon_{\mathrm{td}} \mid \mathrm{X}_{\mathrm{td}}\right]=0 \\
& \epsilon_{t d} \sim \text { i.n.i.d. } N\left(0, \sigma_{t d}^{2}\right) \\
& \sigma_{t d}=\sigma_{0 d} \exp \left(W_{t d}^{\prime} \gamma_{d}\right)
\end{aligned}
$$

where the $(K \times 1)$ and $(L \times 1)$ vectors $X$ and $W$ contain the explanatory variables for the mean and the variance function. The parameter $\sigma_{0 d}$ is a trading day specific volatility constant picking up interday differences in the volatility not explained by the observables $W_{t d}$. Conditional on the set of explanatory variables we assume that the latent variable is mutually independent. Since no restrictions are placed on the stochastic process of $X_{t d}$ and $W_{t d}$ the price process may well reveal unconditional serial dependence. The assumption of normally distributed can easily be relaxed by applying a semi-parametric or a parametrically more flexible approach. Latent price pressure and observable discrete 
price change are related by the following observation rule:

$$
y_{t d}=\left\{\begin{array}{ccc}
-k_{l} & \text { if } & y_{t d}^{*} \in\left(-\infty ; \alpha_{d, 1}\right) \\
\vdots & & \\
-1 & \text { if } & y_{t d}^{*} \in\left(\alpha_{d, k_{l-1}} ; \alpha_{d, k_{l}}\right] \\
0 & \text { if } & y_{t d}^{*} \in\left(\alpha_{d, k_{l}} ; \alpha_{d, k_{l+1}}\right] \\
+1 & \text { if } & y_{t d}^{*} \in\left(\alpha_{d, k_{l+1}} ; \alpha_{d, k_{l+2}}\right] \\
\vdots & & \\
k_{u} & \text { if } & y_{t d}^{*} \in\left(\alpha_{d, k_{l}+k_{u}} ; \infty\right)
\end{array}\right.
$$

where the $\alpha_{d j}$ are unknown threshold parameters that separate the state space of $Y_{t, d}^{*}$. Ticks larger or equal to given size $k_{u}$ are gathered in the uppermost category of $Y_{d, t}$. The analog is true for ticks smaller or equal to size $-k_{l}$. Given $J+1$ categories the intraday model consists of $J+K+L+1$ parameters. However, since the parameters of an ordered response model such as the ordered probit are only identifiable up to a factor of

proportionality only the parameter vector $\lambda_{r}=\left[\begin{array}{lll}\alpha_{d}^{\prime} / \sigma_{0 d} & \alpha_{d}^{\prime} / \sigma_{0 d} & \gamma_{d}^{\prime}\end{array}\right]$ can be identified on an intraday sample. Hence the first stage of estimation yields estimates of $D \cdot(J+K+L)$ auxilary parameters.

\subsection{Combining Intraday Estimates by Means of MDE}

If there is a common structure across trading days one should expect the parameters of the reduced form to be similar across trading days, i.e. price movements should be 
generated by a common set of parameters. The basic idea of the minimum distance estimation method is to find a common set of restrictions on the parameters such that the weighted quadratic distance between the parameters of the structural form and the parameters of the reduced form is minimized. Assume the parameters of the mean and variance function are the same across trading days except the day specific volatilities $\beta_{d}=\beta, \gamma_{d}=\gamma$. Let $\theta_{(1)}=\left[\begin{array}{lllllll}\alpha^{* \prime} & \beta^{* \prime} & \gamma^{\prime} & \sigma_{2}^{*} & \sigma_{3}^{*} & \ldots & \sigma_{D}^{*}\end{array}\right]^{\prime}$ be the $\mathrm{J}+\mathrm{K}+\mathrm{L}+\mathrm{D}-1$ vector of structural parameters, where $\alpha^{*}=\alpha / \sigma_{01}$ and $\beta^{*}=\beta / \sigma_{01}$ are the parameters of the mean and the variance function normalized by the volatility constant of some arbitrarily chosen base period (e.g. the first trading day). The parameter $\sigma_{d}^{*}=\frac{\sigma_{0 d}^{*}}{\sigma_{01}}$ captures the unexplained volatility of trading day $d$ relative to the baseline day. Hence our approach provides interday and intraday measures of volatility. If the hypothesis of an identical structure in the mean and the variance function holds, then there exists a vector of functions $g^{(1)}(\cdot)$ that relates the parameters of the structural form to the auxiliary parameter vector $\lambda_{d}$ in the following way:

$$
g_{d}^{(1)}=g^{(1)}\left(\theta^{(1)}, \hat{\lambda}_{d}\right)=\left[\begin{array}{l}
\alpha^{*} \\
\beta^{*} \\
\gamma
\end{array}\right]-\lambda_{d}
$$

Overall $g_{d}^{(1)}(\cdot), d=1, \ldots, D$ imposes $D \cdot(J+K+L)-(J+K+L+D-1)$ restrictions on the auxiliary parameters. The minimum distance estimator of $\hat{\theta}_{(1)}$ is given by the solution 
of the minimization problem:

$$
\min _{\theta^{(1)}} D^{(1)}\left(\theta^{(1)}\right)=\sum_{d=1}^{D} g^{(1)}\left(\theta^{(1)}, \hat{\lambda}_{d}\right)^{\prime} \hat{\mathrm{V}}\left[\hat{\lambda}_{d}\right]^{-1} g^{(1)}\left(\theta^{(1)}, \hat{\lambda}_{d}\right),
$$

where $\hat{\mathrm{V}}\left[\hat{\lambda_{d}}\right]$ denotes a consistent estimate of the variance covariance matrix of $\hat{\lambda_{d}}$ from the first stage. The estimator resulting from 2.5 is based on the optimal weighting matrix assuming uncorrelatedness for the estimators of the auxiliary parameters across trading days. This property follows directly from the conditional independence assumption of the transaction prices, which needs to be tested by means of tests for serial dependence in nonlinear models. A consistent estimator of the variance covariance matrix of $\hat{\theta}^{(1)}$ is given by:

$$
\hat{\mathrm{V}}\left[\hat{\theta}^{(1)}\right]=\sum_{d=1}^{D}\left(\frac{\partial g_{d}^{(1)^{\prime}}}{\partial \theta^{\prime}} \hat{\mathrm{V}}\left[\hat{\lambda}_{d}\right]^{-1} \frac{\partial g_{d}^{(1)}}{\partial \theta^{\prime}}\right)^{-1}
$$

The objective function evaluated at the minimum $D^{(1)}\left(\hat{\theta}^{(1)}\right)$ serves as a test for the imposed equality of the intraday parameters. It is asymptotically chi-squared distributed with degrees of freedom equal to the number of restrictions imposed and can be shown to be asymptotically equivalent to the Wald or the LM- Test for the same null hypothesis. See Gourieroux and Montfort (1995) sect. 18.1.3, or Burguete, Gallant, and Souza (1982) for Wald and LM type tests in a more general context than ML. It is obvious from the construction of this statistics that a rejection of the null might be due to two reasons. First, one or more day specific restrictions may not hold due to turbulence on the financial markets causing $g_{d}^{(1)}$ to be large in absolute terms. Second, $D^{(1)}\left(\hat{\theta}^{(1)}\right)$ may be high because the precision of a specific intraday estimate is particularly high leading to a large 
weight in the distance function although the structural form parameters and intraday parameters are close.

A model assuming complete structural stability including the day-specific relative volatilities indicates an interesting benchmark case. For the vector of structural parameters to be estimated, the day-specific restriction function is defined as $g_{d}^{(2)}=g^{(2)}\left(\theta^{(2)}, \lambda_{d}\right)=\theta^{(2)}-\lambda_{d}$ imposing $(D-1) \cdot(J+K+L)$ restrictions on the intraday parameters. The corresponding minimum distance estimator is a weighted average of the intraday parameters where the weight increases with the precision of the estimate:

$$
\hat{\theta}^{(2)}=\sum_{d=1}^{D} \hat{A}_{d} \hat{\lambda}_{d}, \quad \text { with } \hat{A}_{d}=\left(\sum_{d=1}^{D} \hat{\mathrm{V}}\left[\hat{\lambda}_{d}\right]^{-1}\right) \cdot \hat{\mathrm{V}}\left[\hat{\lambda}_{d}\right]^{-1}
$$

The difference between the distance statistics $\hat{\theta_{1}}$ and $\hat{\theta_{2}}$ provides an asymptotically $\chi^{2}$ distributed test for the null hypothesis that the volatility parameters are constant across trading days assuming all other restrictions imposed on the first model are true. The degrees of freedom of this test are $D-1$ (i.e. the number of volatility ratios restricted by the second model).

As noted above for a given set of intraday parameter estimates the minimum distance step provides a range of tests for structural stability. Finally, a test of structural stability concerning $d$ trading days can be performed under the maintained hypothesis that the price process of all trading days included can be described by the same model. For instance, testing the null hypothesis that the parameters of trading day $d$ coincide with 
the parameters of all other trading days leads to a Wald- type of statistics of the form:

$$
g^{(1)}\left(\theta^{(1)}, \hat{\lambda}_{d}\right)^{\prime} \hat{\mathrm{V}}\left[\hat{\lambda}_{d}\right]^{-1} g^{(1)}\left(\theta^{(1)}, \hat{\lambda}_{d}\right) \stackrel{a}{\sim} \chi^{2}
$$

which only requires the estimation of $\theta^{(1)}$ as defined by 2.4 .

\section{Data and Model Specification}

\subsection{Data}

Our sample is based on transaction data of the Bund futures trading listed at the London International Financial Futures Exchange (LIFFE). The underlying is a notional 6\% German government bond of DEM 250.000 face value. Any German government bond with a maturity between 8.5 and 10.5 years at contract expiration is allowed to be delivered. There are four contract maturities per year, March, June, September, and December. Prices are denoted in basis points of face value. The tick size is equivalent to a contract value of DEM 25. At the LIFFE, trade is facilitated by an open outcry system during the main business hours followed by computerized trading in the evening. In the sample we investigate, floor trading at the LIFFE starts at 8:30 (CET) and ends around 17:15 h. To avoid distortions caused by the opening and closing procedures we restrict our sample to transactions occuring between 9:00 and 17.00. We arbitrarily choose the period from 08/01/1995 to 08/31/1995, giving us 22 successive trading days. During this period, we analyze the Bund futures contract expiring in September 1995 which was the front month 
contract and thus the most actively traded one. This leaves us with an overall sample of 37,381 observations with an average number of 212 transactions per hour. Tables 1-3 provide summary statistics on trading activity and the price dynamics within and across trading days.

Data files of the LIFFE contain information on time-stamped intraday transaction prices as well as bid and ask quotes. In addition, they yield proxies of trade volumes. ${ }^{8}$ The time stamps contained in the data enable us to compute the time between successive transactions. From bid and ask quotes we compute inside market spreads for each transaction. By far the most observed spreads are of size one tick ( $74.0 \%$ ), spreads larger than two ticks are rarely observed ( $1.2 \%)$. Comparing transaction prices with bid and ask quotes yields an indication for the type of trade. We assume that a transaction is buyer (seller) initiated if it occurs at a price equal or higher (lower) than the previously reported ask (bid) quote. When modeling the price process one could use either the change in transaction prices or the change in mid-quotes between two successive transactions. The first variable is dominated by the well-known bid-ask bounce, see e.g. Roll (1984) or Hausman, Lo, and MacKinlay (1992). Since changes in the mid-quotes seem to be more closely related to the evolution of the assets value we concentrate our analysis on mid-quote chnges.

\footnotetext{
${ }^{8}$ During floor trading hours prices and volumes are reported by pit observers. LIFFE considers the dissemination of price information to be more important than volume information. Additional comparisons with volume traded at the DTB show that the variable is meaningless if individual observations are considered, but conveys valuable information as an aggregate over time.
} 
$98.6 \%$ of observed mid-quote changes fall into the range from -1 to +1 tick, i.e. -1 tick $5.0 \%,-.514 .1 \%, 058.3 \%,+.519 .0 \%$, and $+12.2 \%$. Therefore, it seems appropriate to choose $J=5$ categories for the observable ordered response variable $y_{t}$. The median (mean) time between two successive transactions is 9.5 (16.0) seconds.

Table 1 provides information on the trading activity within and across trading days. The dispersion of trading activity over the days matches the well-known U-shaped pattern as it has been often documented in the literature, e.g.Wood, McInish, and Ord (1985). The least activity is usually observed between 13:00 and 14:00 with a transaction volume of about $45 \%$ of the volume observed between 9:00 and 10:00. Examining individual days, we note that the number of transactions per day varies between 2,572 on $08 / 24 / 95$ and 1,073 on $08 / 30 / 95$. The number of transactions per trading hour ranges from 517 between 15:00 and 16:00 on the 4th and 63 between 13:00 and 14:00 on the 30th.

Information on the price dynamics measured in terms of mid-quote changes is given by table 2. In order to get a better understanding of the sources of variation in the data we decompose the total variation of the mid-quote changes in terms of the within (trading hour) variation, i.e. variation of the price changes for a given trading hour across different trading days, and the between variation, i.e. variation of the price changes between trading hours. Let the price change observed for an hour $h$ (clock time interval) on trading day $d$ be defined as $X_{h d}$. Then its total variation over the sample period can be decomposed 
as follows:

$$
\underbrace{\sum_{h} \sum_{d}\left(x_{h d}-\bar{x}\right)^{2}}_{\text {total variation }}=\underbrace{\sum_{h} \sum_{d}\left(x_{h d}-\bar{x}_{h .}\right)^{2}}_{\text {within variation }}+\underbrace{D \sum_{h}\left(\bar{x}_{h .}-\bar{x}\right)^{2}}_{\text {between variation }}
$$

where:

$$
\bar{x}=\frac{1}{D H} \sum_{h} \sum_{d} x_{h d} \quad \bar{x}_{h .}=\frac{1}{D} \sum_{d} x_{h d}
$$

Based on hourly aggregates we find that $97.1 \%$ of the total variation of the price changes is due to within variation. This result turns out to be robust w.r.t. the choice of frequency of the price change measure. Using price changes on time intervals of 5 (20) minutes the corresponding share of within variation to total variation is $93.2(95.7) \%$, see table 3 . Of course, the strong dominance of the within variation is due to the specific decomposition chosen. Contrary to real panel data $h$ is a subunit of $d$, such that the within variation strongly exploits the time series variation in the data. However, the decomposition clarifies that concentrating on the intraday variation of price changes implies a rather substantial loss of information if there is a common structure that holds across trading days.

\subsection{Model Specification and Evidence from Intraday estimates}

The specification used for our regression model centers around the question of the nature of information diffusion process as analyzed in market microstructure literature. The specification of the mean function is guided by theoretical arguments trying to explain 
local deviations from the martingale hypothesis. For the variance function we recurr to models analyzing market volatility and the clustering of trades.

Lags of the mid-quote changes $(\triangle M Q)$ are included into the mean function (eq. 2.1) for two reasons: First, price changes measured at high frequencies reveal some type of serial dependency. The straightforward interpretation that uninformed trades imply an i.i.d. structure of price changes and that any type of serial dependencies has to originate in the flow of information is somewhat misleading. This becomes evident if one takes models like Admati and Pfleiderer (1988) into account which explicitly allow for discretionary liquidity traders, or if one considers the evidence presented in Easley, Kiefer, and O'Hara (1997) which indicates that uninformed trades need not be i.i.d. However, the occurence of price reversals serves as a feasible indicator for information driven trading. Second, our specification analysis for the intraday ordered probit estimates indicates that lags of the dependent variable have to be included in order to achieve the conditional independence of observations needed for ML estimation. Thus lags of the mid-quote changes up to order three enter the mean function to capture short run dynamics of the price process. Lags of order four and more turn out to be insignificant for all intraday estimates. ${ }^{9}$ Moreover,

\footnotetext{
${ }^{9}$ Misspecification might arise because of omitted variables causing serial dependency in the error term. Based on generalized residuals in the sense of Gourieroux, Montfort, and Trognon (1987) and Gourieroux, Montfort, and Trognon (1985) we test for absence of serial dependence in the ordered probit model. The null could not be rejected for 21 out of 22 trading days. For the sake of brevity, the presentation of the test results is omitted.
} 
we check for potential medium term dynamic effects by two minute aggregates of midquote changes (Agg. $\Delta M Q)$. These turn out to be insignificant once we account for other market microstructure effects in the mean function.

Since microstructure theory suggests that the type of trade is informative, we include two additional variables in the mean function. The variable Bounce captures a bid ask bounce and takes on the value +1 if the transaction is seller initiated at $t-1$ and is buyer initiated at $t$; it takes on the value -1 in the reverse case, and is 0 otherwise. ${ }^{10}$ The variable $R p t$ Ask takes on the value of 1 if two successive transactions at the ask quote are observed and zero otherwise.

In spite of theoretical models like Blume, Easley, and O'Hara (1994) and empirical studies like Easley, Kiefer, and O'Hara (1997) which support the role of volume for the information diffusion we refrain in this study from considering volume explicitly because it was found to be unreliable, but focus instead on the occurence of transactions themselves in order to approximate market imbalances. The use of trade frequency is well supported by the findings of Jones, Kaul, and Lipson (1994) who show on the basis of daily data that volume carries no additional information beyond that which is contained in trade frequency. Furthermore, the work of Easley, Kiefer, and O'Hara (1997) indicates that the inclusion of volume raises the need for a structural model, which is well beyond the scope of this paper. The difference between the number of buyer and seller initiated trades over a certain time interval (TrdDif) enters the mean function. A positive value of this variable

\footnotetext{
${ }^{10}$ See Lee and Ready (1991) for an extensive study covering inference on the direction of trades.
} 
indicates that during the past 2 minutes the majority of trades was buyer initiated. Buyer and seller initiated trading volume is approximated here by the number of transactions per two minute interval in order to test whether market participants observe volume traded or whether this type of market imbalances carries any information. However, since our volume variable can only serve as a crude proxy of the true trading volume we do not attempt to interpret insignificant coefficients for both the mean and variance function as strong evidence against the hypothesis that volume carries additional information beyond that of other variables capturing micro structure effects.

Similar to GARCH type models the variance function contains lags of individual absolute mid-quote changes $(|\Delta M Q|)$ and lags of two minute aggregates of the absolute midquote changes $(A g g .|\Delta M Q|)$ in order to pick up volatility clustering. From a market microstructure point of view time between transactions signals the occurence of new information in the market giving rise to more uncertainty of the true price, as a standard reference see Easley and O'Hara (1992). The time between transactions is hypothesized by Easley and O'Hara (1992) to conveys information which indicates the presence of private information in the market, leading to a subsequent adjustment of prices. In the following we use lags of the time between transactions $(\Delta t)$ as well as the mean time between transactions over two minute intervals $(\overline{\Delta t})$ as explanatory variables for the variance of a price change. The past spread is included into the regression model for several reasons. On the one hand a spread larger than the normal one might among other things indicate that the presence of private information in the market prompts uninformed traders to raise 
their spread as a protective measure, see e.g. Glosten and Milgrom (1985) or Glosten and Harris (1988). On the other hand, the reasoning put forward by Admati and Pfleiderer (1988) suggests that liquidity traders who have some discretion with respect to their timing of transactions will seek periods of low trading costs and thus producing some volatility clustering on the market. The dummy variable Spread for the spread enters the variance function. This variable takes on the value 1 if the tick size of the spread is 2 or larger.

Intraday seasonalities of the volatility are a well-known phenomenon. We account for these patterns through time dummies in the variance function for each hour of the trading day, where the trading hour between 9:00 and 10:00 serves as the reference category. Note that the inclusion of the time dummies is crucial for the interpretation of results concerning the trade frequency. If these time dummies are omitted the time between transactions does not solely capture the effects of short-lived, local variations of the trade frequency but is likely to be dominated by daily seasonalities, particularly by the lunch hour effect, see e.g. Dacorogna, Müller, Nagler, Olsen, and Pictet (1993).

Table 4 provides insight into the qualitative nature of the estimated determinants of transaction price changes based on the ordered probit estimates for the 22 trading days. Detailed estimation results are omitted since hardly any straightforward conclusions can be drawn concerning our main question, whether there is a commom market microstructure, on the basis of 22 individual regressions. One striking result is that the signs of 
estimated coefficients are largely stable across trading days. This may be taken as a first indication toward the existence of a common structure. Also, there is no set of variables with nearly equal shares of significantly positive or negative coefficients indicating a regime shift or a structural break. Quite a number of the estimated coefficients turn out to be insignificant. In particular, this holds for the coefficients on higher order lags. For most of the trading days we are not able to find intraday seasonality as it is captured by the dummy variables.

\section{Common Market Microstructure Across Trading Days: Empirical Evidence}

The deficiencies of comparing estimates for single trading days are quite obvious. Given the baseline intraday specification of the previous section with 53 parameters $(J=4, K=$ $19, L=30$ ) we end up with an overall number of 1,166 parameters for the 22 trading days. Observed differences in size between the estimated coefficients may occur by chance or have a substantive background. Some of the coefficients obtained by intraday estimates do not even have a clear-cut interpretation. For instance, intraday time dummies may capture daily seasonalities but can also reflect the impact of singular news events on a particular trading day. Moreover, different threshold parameters do not make much sense from a theoretical point of view. 
As outlined in section 2 minimum distance estimation provides a framework of testing for, and imposing, a common parameter structure. Table 6 gives the results of the minimum distance estimation assuming equality of all coefficients across trading days with the exception of the daily volatility ratios $\sigma_{d}^{*}=\frac{\sigma_{0 d}^{*}}{\sigma_{01}}$ as defined by the parameter vector $\theta_{(1)}$. The corresponding minimum distance statistics, reported in table 7 , however, indicate that the imposed parameter restrictions clearly have to be rejected.

The rejection of this specification leads to additional questions: First of all, are there at least some subperiods in the sample which actually share a common price process? This might be true if there are only a few exceptional days which lead to the rejection of an overall common structure. In this case we are further interested in the underlying economic reasons for the departing structures of particular days. In particular, we would like to infer whether all dimensions of the price process are equally affected by this disruption?

Therefore, in a second step we check for a more flexible but sufficiently parsimoneous specification that incorporates a large fraction of trading days. This is done by testing the null hypothesis which states that parameters of trading day $d$ are identical with coresponding ones of all other trading days using the $\chi^{2}$-test introduced in section 2 . The results of this test are given in table 8 . Interestingly, the null can only be rejected for 4 trading days at the 1-percent level, indicating that a limited number of individual trading days may cause an overall rejection of the most parsimoneous specification we started with. The four particular days are August 4th as well as the period of August 22nd through 
24th. These days are dominated by the major news events of August 1995: On August 4th, July's employment figures for the U.S. were released. The 22nd is actually marked by two major news releases. First, the German Bundesbank announced an observed contraction of M3. Second, the FOMC decided to keep key interest rates at the current level. However, this decision was released after closing of the Bund futures trading so that this new event actually effected trading on the 23rd. By inspection of the Reuters money market news tape it is apparent that FOMC's decision was not in accordance with the market consensus. Finally, on 24th the German Bundesbank announced a 50 basis point cut in two of the German key interest rates, namely in the lombard and the discount rate. Since it is the major goal of this paper to develop an empirical framework for the analysis of shifts in the price process we refrain from hypothesizing on potential links between the price process and economic fundamentals. At this stage of our research we regard our findings merely as a pointer towards future research concerning the effect of news releases on the price process.

The presented evidence suggests splitting sample (A) into two parts. One subsample (B) consists of 18 trading days (B) selected on the results obtained by the $\xi_{3}$ statistics decribed above. The other sample $(\mathrm{C})$ consists of the four deviating trading days. Estimating the baseline specification on the basis of sample B we cannot reject the hypothesis of common structure, see table 7. This finding is not merely caused by a reduction of the sample size, which still contains 29,901 observations, but rather by the selection of trading days with 
a homogenous price process. Given the large sample size, which often leads to a rejection of any type of null hypothesis we regard this finding as somewhat surprising.

On the other hand we clearly have to reject the hypothesis of a common price process for sample C. Obviously the major news events on these trading days generated unique, day specific price processes. Hence by testing for periods with a homogeneous price process we finally end up with a parsimoneous specification for the whole sample period of the 22 trading days that requires less than a quarter of the number of parameters used for the separate intraday estimates.

A comparison of the size of the coefficients and the sign pattern between the estimates for subperiods $\mathrm{B}$ and $\mathrm{C}$ reveals that, despite the rejection of total homogeneity of trading days, the impact of market microstructure variables is very similar. In particular, this holds for the factors driving the mean price change and to a lesser extent for the volatility's explanatory variables.

The minimum distance estimates are more precise compared to the intraday estimates. While many higher order lags of the explanatory variables are insignificant for the separate intraday estimates, for instance, we can detect a significant bid-ask momentum up to a lag of order five. Moreover, our approach nicely detects intraday seasonalities in the volatility of the price change with peeks around 13:00 to 15:00.

Finally, we use the relative volatility parameter $\sigma_{d}^{*}=\frac{\sigma_{0 d}^{*}}{\sigma_{01}}$ to check for event dominated trading days. In figure 1 we compare the relative daily volatilities obtained by our mini- 
mum distance approach to the daily volatility constants (stadardized by the first trading day) from a GARCH(1,1) model estimated on five minute aggregates. The shape of the volatility ratios is similar but the GARCH ratios are clearly more pronounced. The striking differences of GARCH and the ordered probit - minimum distance estimates between $8 / 10 / 95$ and $8 / 18 / 95$ can well be explained by the nature of the the GARCH specification being used which does not correct for specific market microstructure effects in the mean of the price process. On the other hand, the observable differences for the time period $8 / 25 / 95$ to $8 / 30 / 95$ can be attributed to the fact that our estimator does not incorporate autoregressive volatility effects in the variance function.

\section{Conclusions}

In this paper we analyze the determinants of transaction price changes for the BUND future trading at the LIFFE on the basis of the 22 subsequent trading days. The minimum distance estimation technique applied combines the intraday estimates optimally while taking into account the discrete nature of price jumps at the transaction level and the irregularly spaced time intervalls between transactions. Our approach enables us to work out a common structure across trading days and to disentangle the pecularities of certain trading days which are marked by certain news events. Despite the large sample size of around 1.7 thousand transactions per trading day that usually gives rise to the rejection of any null hypothesis on the equality of regression coefficients we find a common structure 
for 18 out of 22 trading days. On the other hand exceptional trading days lead to structural breaks rendering simple pooling estimates inconsistent. In particular, news events are more likely to affect the variance function than the mean function. Therefore, more attention should be payed to the fact that prominent news events distort the way that information is processed in financial markets.

By its nature our approach is, of course more explorative than structural. At most our estimation results provide evidence as to whether some behavioral hypothesis derived from the highly stylized market microstructure models are consistent with transactions data. Conditional on the (short-run) history of the trading process we find the type of orders to have a significant impact on the mean of price changes. We are able to identify something like a bid-ask momentum and an effect of consecutive buyer initiated trades. This feature of the price process, however, needs to be interpreted in conjunction with the negative feedback introduced by lagged mid-quote changes. The time between transactions is informative regarding the volatility of price changes. More frequent trading implies a higher variance per transaction. Spread size enters the variance function with a positive sign, indicating that larger spreads imply a higher variance per transaction.

Our empirical findings are in accordance with the hypothesis that there is a learning mechanism present at the micro level based on order flow. In particular interpreting the time between transactions in the sense of Easley and O'Hara (1992) and Easley, Kiefer, and O'Hara (1997) as an indication for information present in the market, we conclude 
that it is indeed information and not liquidity which drives volatility. This is supported by the fact that the explanatory variables capturing an imbalance of supply and demand were hardly ever found to be significant.

The approach presented here offers numerous avenues for future research. The merits of the approach should be checked in the light of transaction prices of different financial markets. Since the computational burden involved is fairly limited, the minimum distance technique nicely qualifies for the analysis of intraday seasonalities. Finally, more research should be devoted to the endogeneity of the time between transactions, volume and transactions costs leading to econometric specifications that treat all three variables as endogeneous.

\section{References}

Admati, A., And P. Pfleiderer (1988): "A Theory of Intra-Day Patterns: Volume and Price Variability," Review of Financial Studies, 1, 3-40.

Ait-Sahalia, Y. (1998): "Dynamic Equilibrium and Volatility in Financial Asset Markets," Journal of Econometrics, 84, 93-127.

Andersen, T. G., And T. Bollerslev (1997a): "Heterogeneous Information Arrivals and Return Volatility Dynamics: Uncovering the Long-Run in High Frequency Returns," Journal of Finance, 52, 975-1005.

(1997b): "Intraday Periodicity and Volatility Persistence in Financial Markets," Journal of Empirical Finance, 4, 115-158.

(1998): "Deutsche Mark-Dollar Volatility: Intraday Activity Patterns, Macroeconomic Announcements, and Longer Run Dependencies," Journal of Finance, 53, 219-265.

Andersen, T. G., T. Bollerslev, and A. Das (1998): "Testing for Market Microstructure Effects in Intraday Volatility: A Reassessment of the Tokyo FX Experiment," Discussion Paper 6666, NBER Working Paper Series. 
BALl, C. (1988): "Estimation Bias Induced by Discrete Security Prices," Journal of Finance, 43, 841-865.

Blume, L., D. Easley, and M. O'Hara (1994): "Market Statistics and Technical Analysis: The Role of Volume," Journal of Finance, 49, 153-181.

Bollerslev, T., and I. Domowitz (1993): "Trading Patterns and Prices in the Interbank Foreign Exchange Market," Journal of Finance, 48, 1421-1443.

Bollerslev, T., And M. Melvin (1994): "Bid-Ask Spreads and Volatility in the Foreign Exchange Market - An Empirical Analysis," Journal of International Economics, $36,355-372$.

Burguete, J. F., A. R. Gallant, and G. Souza (1982): "On Unification of the Asymptotic Theory of Nonlinear Econometric Models," Econometric Reviews, 1, 151190.

Cho, D. C., And E. W. Frees (1988): "Estimating the Volatility of Discrete Stock Prices," Journal of Finance, 43, 451-466.

Dacorogna, M. M., U. A. Müller, R. J. Nagler, R. B. Olsen, and O. V. Pictet (1993): “A Geographical Model for the Daily and Weekly Seasonal Volatility in the Foreign Exchange Market," Journal of International Money and Finance, 12, $413-438$.

Easley, D., N. M. Kiefer, And M. O'Hara (1997): "The Information Content of the Trading Process," Journal of Empirical Finance, 4, 159-186.

Easley, D., N. M. Kiefer, M. O’Hara, and J. B. Paperman (1996): "Liquidity, Information, and Infrequently Traded Stocks," Journal of Finance, 51, 1405-1436.

Easley, D., And M. O’Hara (1992): “Time and the Process of Security Price Adjustment," Journal of Finance, 47, 577-607.

Engle, R. F. (1996): "The Econometrics of Ultra-High Frequency Data," Discussion paper, Department of Economics, UCSD.

Engle, R. F., And J. R. Russell (1997): "Forecasting the Frequency of Changes in Quoted Foreign Exchange Prices with the Autoregressive Conditional Duration Model," Journal of Empirical Finance, 4, 187-212.

Glosten, L., and P. Milgrom (1985): "Bid, Ask and Transaction Prices in a Specialist Market with Heterogeneously Informed Traders," Journal of Financial Economics, 14, $71-100$. 
Glosten, L. R., And L. E. Harris (1988): "Estimating the Components of the Bid/Ask Spread," Journal of Financial Economics, 21, 123-142.

Goodhart, C. A. E., and M. O’Hara (1997): "High Frequency Data in Financial Markets: Issues and Applications," Journal of Empirical Finance, 4, 73-114.

Gourieroux, C., And A. Montfort (1995): Statistics and Econometric Models. Cambridge University Press, Cambridge.

Gourieroux, C., A. Montfort, and A. Trognon (1985): "A General Approach to Serial Correlation," Econometric Theory, 1, 315-340. (1987): "Generalized Residuals," Journal of Econometrics, 34, 5-32.

Guillaume, D. M., M. M. Dacorogna, R. R. Dave, U. A. Müller, R. B. Olsen, And O. V. Pictet (1997): "From the Bird's Eye to the Microscope: A Survey of New Stylized Facts of the Intra-Daily Foreign Exchange Markets," Finance and Stochastics, $1,95-129$.

HARRIS, L. (1990): "Estimation of Stock Variances and Serial Covariances from Discrete Observations," Journal of Financial and Quantitative Analysis, 25, 291-306.

HARris, L. E. (1994): "Minimum Price Variations, Discrete Bid-Ask Spreads, and Quotation Sizes," Review of Financial Studies, 7, 149-178.

Hasbrouck, J. (1991): "Measuring the Information Content of Stock Trades," Journal of Finance, 66, 179-206.

Hausman, J. A., A. W. Lo, And A. C. MacKinlay (1992): "An Ordered Probit Analysis of Transaction Stock Prices," Journal of Financial Economics, 31, 319-379.

Jones, C. M., G. Kaul, and M. L. Lipson (1994): "Transactions, Volume, and Volatility," Review of Financial Studies, 7, 631-651.

Jones, C. M., O. Lamont, and R. L. Lumsdaine (1998): "Macroeconomic News and Bond Market Volatility," Journal of Financial Economics, 47, 315-337.

Kim, O., And R. E. Verrechia (1991): "Market Reactions to Anticipated Announcements," Journal of Financial Economics, 30, 273-309.

Kodde, D. A., F. C. Palm, and G. A. Pfann (1990): "Asymptotic Least-Squares Estimation Efficiency Considerations and Applications," Journal of Applied Econometrics, 5, 229-243.

Lee, C. M. C., and M. J. Ready (1991): "Inferring Trade Direction from Intraday Data," Journal of Finance, 46, 733-746. 
Maddala, G. S., and M. Nimalendran (1995): “An Unobserved Component Panel Data Model to Study the Effect of Earnings Surprises on Stock Prices, Trading Volumes, and Spreads," Journal of Econometrics, 68, 229-242.

McInish, T., And R. Wood (1992): "An Analysis of Intraday Patterns in Bid/Ask Spreads for NYSE Stocks," Journal of Finance, 47, 753-764.

Roll, R. (1984): "A Simple Implicit Measure of the Effective Bid-Ask Spread in an Efficient Market," Journal of Finance, 39, 1127-1139.

Russell, J. R., And R. F. Engle (1998): "Econometric Analysis of Discrete-Valued, Irregularly-Spaced Financial Transactions Data Using a New Autoregressive Conditional Multinomial Model," Discussion paper, presented at Second International Conference on High Frequency Data in Finance, Zurich, Switzerland.

Wood, R. A., T. H. McInish, And J. K. ORd (1985): "An Investigation of Transactions Data for NYSE Stocks," Journal of Finance, 40, 723-741. 
Table 1: Number of transactions per hour for each trading day, total number of transactions per day and number of transactions in specific hours over the entire sample. Descriptive statistics of BUND futures floor trading at LIFFE in London between 08/01/95 and 08/31/95. There was no trading on 08/28/95 due to the late summer bank holiday. Data compiled from 'LIFFE tick data' CD-ROM.

\begin{tabular}{|c|c|c|c|c|c|c|c|c|c|c|c|c|}
\hline & $8: 30-9: 00$ & 9:00-10:00 & $10: 00-11: 00$ & $11: 00-12: 00$ & $\begin{array}{r}\text { Sampl } \\
12: 00-13: 00\end{array}$ & $\begin{array}{l}\text { Period } \\
\text { 13:00-14:00 }\end{array}$ & $14: 00-15: 00$ & $15: 00-16: 00$ & $16: 00-17: 00$ & $17: 00-17: 15$ & $\begin{array}{r}\text { Total } \\
9: 00-17: 00\end{array}$ & $\begin{array}{r}\text { Total } \\
8: 30-17: 15\end{array}$ \\
\hline $08 / 01 / 95$ & 137 & 239 & 134 & 102 & 130 & 85 & 114 & 229 & 367 & 92 & 1400 & 1629 \\
\hline $08 / 02 / 95$ & 246 & 352 & 282 & 168 & 164 & 128 & 325 & 424 & 374 & 90 & 2217 & 2553 \\
\hline $08 / 03 / 95$ & 231 & 307 & 280 & 207 & 139 & 154 & 329 & 309 & 426 & 105 & 2151 & 2487 \\
\hline $08 / 04 / 95$ & 74 & 234 & 154 & 210 & 96 & 64 & 451 & 517 & 336 & 116 & 2062 & 2252 \\
\hline $08 / 07 / 95$ & 92 & 179 & 154 & 140 & 213 & 99 & 185 & 261 & 218 & 66 & 1449 & 1607 \\
\hline $08 / 08 / 95$ & 207 & 327 & 183 & 236 & 140 & 130 & 268 & 207 & 269 & 79 & 1760 & 2046 \\
\hline $08 / 09 / 95$ & 149 & 261 & 339 & 171 & 129 & 83 & 199 & 208 & 184 & 41 & 1574 & 1764 \\
\hline $08 / 10 / 95$ & 104 & 159 & 102 & 99 & 243 & 156 & 345 & 339 & 302 & 71 & 1745 & 1920 \\
\hline $08 / 11 / 95$ & 128 & 287 & 163 & 159 & 151 & 66 & 338 & 297 & 314 & 111 & 1775 & 2014 \\
\hline $08 / 14 / 95$ & 241 & 259 & 215 & 260 & 149 & 91 & 168 & 179 & 275 & 79 & 1596 & 1916 \\
\hline $08 / 15 / 95$ & 105 & 187 & 240 & 242 & 168 & 94 & 456 & 335 & 321 & 84 & 2043 & 2232 \\
\hline $08 / 16 / 95$ & 238 & 355 & 273 & 240 & 110 & 243 & 264 & 347 & 256 & 78 & 2088 & 2404 \\
\hline $08 / 17 / 95$ & 186 & 249 & 220 & 174 & 141 & 104 & 246 & 193 & 398 & 95 & 1725 & 2006 \\
\hline $08 / 18 / 95$ & 184 & 301 & 199 & 166 & 117 & 77 & 95 & 123 & 237 & 43 & 1315 & 1542 \\
\hline $08 / 21 / 95$ & 176 & & 216 & 204 & 126 & 77 & 125 & 169 & 229 & 67 & & 1584 \\
\hline $08 / 22 / 95$ & 193 & 347 & 191 & 171 & 159 & 67 & 114 & 174 & 208 & 69 & 1431 & 1693 \\
\hline $08 / 23 / 95$ & 168 & 308 & 179 & 62 & 145 & 70 & 183 & 179 & 189 & 44 & 1415 & 1627 \\
\hline $08 / 24 / 95$ & 121 & 257 & 188 & 262 & 207 & 469 & 434 & 399 & 356 & 89 & 2572 & 2782 \\
\hline $08 / 25 / 95$ & 237 & 295 & 150 & 214 & 124 & 73 & 198 & 283 & 259 & 82 & 1596 & 1915 \\
\hline $08 / 29 / 95$ & 155 & 268 & 187 & 162 & 121 & 95 & 185 & 178 & 268 & 67 & 1464 & 1686 \\
\hline $\begin{array}{l}08 / 30 / 95 \\
08 / 31 / 95\end{array}$ & $\begin{array}{l}128 \\
66\end{array}$ & $\begin{array}{l}171 \\
195\end{array}$ & $\begin{array}{r}97 \\
172\end{array}$ & $\begin{array}{l}133 \\
230\end{array}$ & $\begin{array}{r}77 \\
110\end{array}$ & $\begin{array}{r}63 \\
102\end{array}$ & $\begin{array}{l}189 \\
192\end{array}$ & $\begin{array}{l}198 \\
288\end{array}$ & $\begin{array}{l}145 \\
300\end{array}$ & $\begin{array}{l}33 \\
56\end{array}$ & $\begin{array}{l}1073 \\
1589\end{array}$ & 1234 \\
\hline Total & 3566 & 5732 & 4318 & 4112 & 3159 & 2590 & 25403 & 25836 & 6231 & $\overline{1657}$ & 37381 & 42604 \\
\hline
\end{tabular}


Table 2: Mid quote changes over one hour of trading and total change of mid quote over one trading day. Quotes are generated by observed bid and ask quotes preceeding a transaction. Descriptive statistics of BUND futures floor trading at LIFFE in London between 08/01/95 and 08/31/95. Data compiled from 'LIFFE tick data' CD-ROM.

\begin{tabular}{|c|c|c|c|c|c|c|c|c|c|c|c|c|}
\hline & 8:30-9:00 & $9: 00-10: 00$ & $10: 00-11: 00$ & $11: 00-12: 00$ & $\begin{array}{c}\text { Sample } \\
\text { 12:00-13:00 }\end{array}$ & $\begin{array}{l}\text { Period } \\
\text { 13:00-14:00 }\end{array}$ & $14: 00-15: 00$ & $15: 00-16: 00$ & $16: 00-17: 00$ & $17: 00-17: 15$ & $\begin{array}{r}\text { Total } \\
9: 00-17: 00\end{array}$ & $\begin{array}{r}\text { Total } \\
\text { 8:30-17:15 }\end{array}$ \\
\hline $08 / 01 / 95$ & -2.0 & 5.0 & -4.0 & 3.0 & 2.5 & 0.0 & -1.5 & -4.0 & -11.0 & -4.0 & -10.0 & \\
\hline $08 / 02 / 95$ & 31.0 & -0.5 & 4.5 & -2.5 & 4.0 & -2.0 & -0.5 & 17.0 & -6.5 & 5.0 & 13.5 & 49.5 \\
\hline $08 / 03 / 95$ & -2.5 & -8.0 & 5.0 & -4.0 & 7.0 & -1.5 & -12.5 & 6.5 & 13.5 & -3.0 & 6.0 & 0.5 \\
\hline $08 / 04 / 95$ & 0.5 & 9.0 & 2.0 & 0.0 & -2.5 & -4.5 & 5.0 & 7.0 & 6.5 & 4.5 & 22.5 & 27.5 \\
\hline $08 / 07 / 95$ & 1.5 & 1.0 & 2.0 & -3.0 & -7.0 & -1.0 & -2.0 & 3.0 & 10.0 & -5.0 & 3.0 & -0.5 \\
\hline $08 / 08 / 95$ & 5.0 & -8.5 & 0.5 & -3.0 & -3.0 & -4.0 & 6.0 & -4.5 & 5.5 & -5.0 & -11.0 & -11.0 \\
\hline $08 / 09 / 95$ & -3.0 & 4.0 & 5.0 & -5.0 & 1.0 & -0.5 & -0.5 & -2.0 & 3.5 & 1.5 & 5.5 & 4.0 \\
\hline $08 / 10 / 95$ & -3.0 & 2.0 & -3.0 & 4.0 & 5.5 & 3.5 & 13.0 & -6.0 & 4.0 & 1.0 & 23.0 & 21.0 \\
\hline $08 / 11 / 95$ & -2.5 & -1.0 & 1.5 & 1.5 & 5.0 & -5.0 & 5.0 & -4.0 & -16.5 & -9.5 & -13.5 & -25.5 \\
\hline $08 / 14 / 95$ & -12.0 & 0.0 & -12.0 & 6.0 & -4.0 & 3.0 & -3.5 & 4.5 & -1.0 & -2.0 & -7.0 & -21.0 \\
\hline $08 / 15 / 95$ & 3.0 & -7.0 & -7.0 & -9.0 & -5.0 & -3.0 & -9.5 & 10.0 & -17.5 & 3.5 & -48.0 & -41.5 \\
\hline $08 / 16 / 95$ & 5.5 & -1.0 & 4.0 & -1.0 & -2.0 & -14.5 & 2.0 & 5.0 & -4.0 & 11.5 & -11.5 & 5.5 \\
\hline $08 / 17 / 9$ & 9.5 & 0.0 & -4.5 & -1.0 & -3.0 & -1.0 & 6.0 & -2.0 & -16.0 & 10.0 & -21.5 & -2.0 \\
\hline $08 / 18 / 95$ & 9.5 & 5.0 & 2.0 & & 2.0 & -1.0 & 5.5 & -3.5 & 0.0 & -3.0 & 3.0 & 9.5 \\
\hline $08 / 21 / 95$ & 12.0 & 0.0 & 6.0 & -1.0 & -1.0 & -3.0 & 7.0 & -4.0 & 13.0 & 1.0 & 17.0 & 30.0 \\
\hline $08 / 22 / 95$ & -0.5 & 1.0 & 0.0 & -5.0 & 1.0 & -2.0 & 1.0 & -0.5 & 2.5 & -3.0 & -2.0 & -5.5 \\
\hline $08 / 23 / 95$ & 16.0 & -6.5 & -1.0 & -2.0 & 0.0 & -2.0 & -4.0 & 4.0 & -3.0 & -1.0 & -14.5 & 0.5 \\
\hline $\begin{array}{l}08 / 24 / 95 \\
08 / 25 / 25\end{array}$ & 2.0 & $\begin{array}{l}1.5 \\
4.5\end{array}$ & -4.5 & -13.0 & 5.0 & 5.0 & -2.5 & -16.5 & 18.0 & -3.5 & -7.0 & -8.5 \\
\hline $\begin{array}{l}08 / 25 / 95 \\
08 / 20 / 95\end{array}$ & $\begin{array}{r}9.0 \\
-1.5\end{array}$ & $\begin{array}{l}-4.5 \\
-4.5\end{array}$ & -1.0 & $\begin{array}{l}-5.0 \\
-0.5\end{array}$ & -3.0 & 3.5 & 2.0 & -1.0 & -6.5 & 2.5 & -15.5 & -4.0 \\
\hline $\begin{array}{l}08 / 29 / 95 \\
08 / 30 / 95\end{array}$ & $\begin{array}{l}-1.5 \\
-5.5 \\
\end{array}$ & $\begin{array}{l}-4.5 \\
-0.5\end{array}$ & $\begin{array}{r}-6.5 \\
1.0\end{array}$ & $\begin{array}{l}-0.5 \\
-1.0\end{array}$ & $\begin{array}{l}5.5 \\
2.0\end{array}$ & $\begin{array}{r}-7.0 \\
1.5\end{array}$ & $\begin{array}{r}0.5 \\
-1.5\end{array}$ & $\begin{array}{l}-3.0 \\
-2.0\end{array}$ & 5.5 & 5.0 & -10.0 & $\begin{array}{l}-6.5 \\
-5.0\end{array}$ \\
\hline $\begin{array}{l}08 / 30 / 95 \\
08 / 31 / 95\end{array}$ & $\begin{array}{l}-5.5 \\
-1.5\end{array}$ & $\begin{array}{l}-0.5 \\
-5.5\end{array}$ & $\begin{array}{r}1.0 \\
-13.0\end{array}$ & $\begin{array}{r}-1.0 \\
0.5\end{array}$ & $\begin{array}{r}2.0 \\
-2.0\end{array}$ & $\begin{array}{r}1.5 \\
-1.0\end{array}$ & $\begin{array}{l}-1.5 \\
-3.0\end{array}$ & $\begin{array}{r}-2.0 \\
4.0\end{array}$ & $\begin{array}{r}0.0 \\
-3.0\end{array}$ & $\begin{array}{l}1.0 \\
0.0\end{array}$ & $\begin{array}{r}-0.5 \\
-23.0\end{array}$ & $\begin{array}{r}-5.0 \\
-24.5\end{array}$ \\
\hline
\end{tabular}


Table 3: Decomposition of the variation in price changes over $60,40,20$, and 5 minutes within and between trading days. Note: ${ }^{1}$ The non-integer value is due to missing observations on five minute price changes.

\begin{tabular}{ll|rrrr} 
& & Observations & Sum of squares & Variance & Share \\
\hline Variation on 60 min & total & 176 & 5769.64 & 5.74 & 100.00 \\
& within & 8 & 5601.27 & 5.66 & 97.08 \\
& between & 22 & 168.36 & 1.05 & 2.92 \\
\hline Variation on 40 min & total & 286 & 8289.96 & 5.39 & 100.00 \\
& within & 13 & 7720.46 & 5.20 & 93.13 \\
& between & 22 & 569.50 & 1.47 & 6.87 \\
\hline Variation on 20 min & total & 572 & 9779.32 & 4.14 & 100.00 \\
& within & 26 & 9118.68 & 4.00 & 93.24 \\
& between & 22 & 660.64 & 1.10 & 6.76 \\
\hline Variation on 5 min & total & 2294 & 11210.85 & 2.21 & 100.00 \\
& within & 105 & 10730.71 & 2.16 & 95.72 \\
& between & 21.85 & 480.14 & 0.46 & 4.28 \\
\hline
\end{tabular}


Table 4: Estimation results of 22 ordered probits with observable heteroscedasticity. Number of significant positive and negative coefficients, as well as the number of insignificant coefficients.

\begin{tabular}{|c|c|c|c|c|}
\hline & & \multicolumn{2}{|c|}{ significant } & insignificant \\
\hline \multicolumn{5}{|c|}{ Thresholds } \\
\hline$\alpha_{1}$ & & & 22 & \\
\hline$\alpha_{2}$ & & & 22 & \\
\hline$\alpha_{3}$ & & 22 & & \\
\hline$\alpha_{4}$ & & 22 & & \\
\hline \multicolumn{5}{|c|}{ Mean parameters } \\
\hline \multirow[t]{3}{*}{$\Delta M Q$} & 1 & & 10 & 12 \\
\hline & 2 & & 10 & 12 \\
\hline & 3 & & 1 & 21 \\
\hline \multirow[t]{3}{*}{ Agg. $\triangle M Q$} & 1 & & 1 & 21 \\
\hline & 2 & & & 22 \\
\hline & 3 & & 1 & 21 \\
\hline \multirow[t]{5}{*}{ Bounce } & 1 & 22 & & \\
\hline & 2 & 22 & & \\
\hline & 3 & 18 & & 4 \\
\hline & 4 & 12 & & 10 \\
\hline & 5 & 7 & & 15 \\
\hline \multirow[t]{5}{*}{ RptAsk } & 1 & 22 & & \\
\hline & 2 & 19 & & 3 \\
\hline & 3 & 14 & & 8 \\
\hline & 4 & 1 & & 21 \\
\hline & 5 & 3 & & 19 \\
\hline \multirow[t]{3}{*}{$\overline{T r d D i f}$} & 1 & & & 22 \\
\hline & 2 & & 1 & 21 \\
\hline & 3 & & & 22 \\
\hline \multicolumn{5}{|c|}{ Variance parameters } \\
\hline \multirow[t]{4}{*}{$|\Delta M Q|$} & 1 & & & 22 \\
\hline & 2 & 2 & & 20 \\
\hline & 3 & 2 & 1 & 19 \\
\hline & 4 & 3 & & 19 \\
\hline \multirow[t]{3}{*}{ Agg. $|\Delta M Q|$} & 0 & 3 & & 19 \\
\hline & 1 & 1 & & 21 \\
\hline & 2 & & 1 & 21 \\
\hline
\end{tabular}




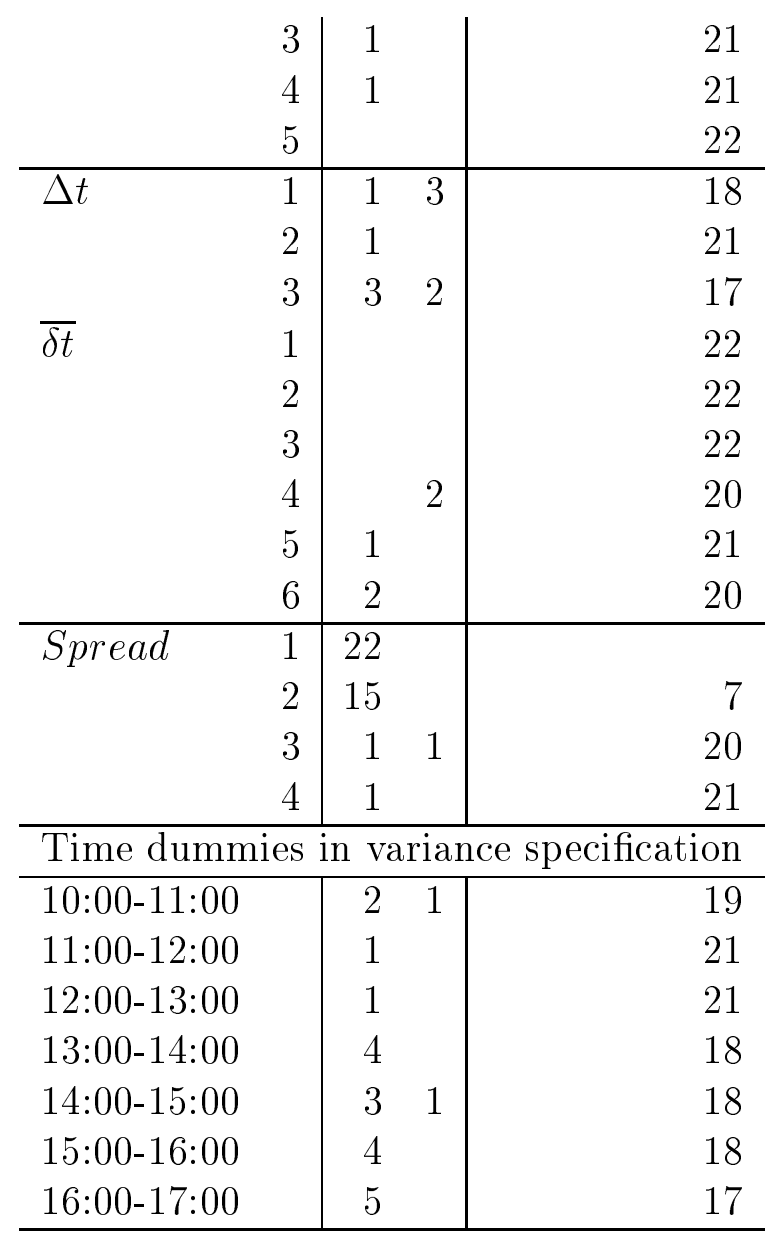


Table 5: News events in August 1995. Data compiled from Olsen \& Associates' tapes of Reuter's AAMM news screen. Date Data Data German FOMC Major

\begin{tabular}{lrrrrl} 
& U.S. & Bond Rate & & news item \\
\hline $08 / 01 / 95$ & 7 & 3 & 0 & 0 & U.S. growth data \\
$08 / 02 / 95$ & 12 & 0 & 0 & 0 & U.K. trade \& consumer data \\
$08 / 03 / 95$ & 16 & 9 & 1 & 0 & Waiting for U.S. employment data \\
$08 / 04 / 95$ & 31 & 16 & 1 & 0 & U.S. employment data \\
$08 / 07 / 95$ & 9 & 0 & 0 & 0 & - \\
$08 / 08 / 95$ & 11 & 1 & 0 & 0 & Bundesbank sets tender for 14-day repos, German M3 growth \\
$08 / 09 / 95$ & 2 & 0 & 3 & 0 & Bundesbank lowers repo \\
$08 / 10 / 95$ & 12 & 3 & 2 & 0 & Bundesbank holds discount and lombard steady, \\
& & & & & U.S. producer and jobless claims \\
$08 / 11 / 95$ & 17 & 7 & 0 & 0 & U.S. CPI data \\
$08 / 14 / 95$ & 5 & 0 & 0 & 0 & U.K. PPI data, \\
$08 / 15 / 95$ & 12 & 4 & 2 & 0 & U.S. industrial output \\
$08 / 16 / 95$ & 12 & 3 & 2 & 0 & Bundesbank holds repo rate steady \\
$08 / 17 / 95$ & 23 & 5 & 0 & 0 & U.K. RPI \\
$08 / 18 / 95$ & 4 & 0 & 1 & 6 & - \\
$08 / 21 / 95$ & 8 & 0 & 1 & 7 & U.K. GDP \\
$08 / 22 / 95$ & 3 & 0 & 1 & 13 & German M3 contracted \\
$08 / 23 / 95$ & 6 & 0 & 4 & 1 & FOMC holds discount and lombard steady \\
$08 / 24 / 95$ & 14 & 5 & 4 & 0 & Bundesbank lowers discount and lombard \\
$08 / 25 / 95$ & 8 & 3 & 1 & 1 & U.S. homes \\
$08 / 29 / 95$ & 4 & 2 & 0 & 0 & U.S. consumer confidence \\
$08 / 30 / 95$ & 12 & 3 & 0 & 0 & Waiting for U.S. payroll data \\
$08 / 31 / 95$ & 14 & 4 & 0 & 0 & U.S. payroll data \\
\hline
\end{tabular}


Table 6: Minimum distance estimation results for August (A), for August excluding the 4th, and the 22nd through the 24th (B), and for four days, i.e. August 4, August 22-24 (C).

\begin{tabular}{|c|c|c|c|c|c|c|c|}
\hline \multirow{2}{*}{\multicolumn{2}{|c|}{ Sample }} & \multicolumn{2}{|l|}{ A } & \multicolumn{2}{|l|}{ B } & \multicolumn{2}{|l|}{$\mathrm{C}$} \\
\hline & & \multicolumn{6}{|c|}{ Thresholds } \\
\hline$\alpha_{1}$ & & -1.6614 & $* * *$ & -1.5209 & $* * *$ & -1.7003 & $* * *$ \\
\hline$\alpha_{2}$ & & -0.7607 & $* * *$ & -0.6951 & $* * *$ & -0.7893 & *** \\
\hline$\alpha_{3}$ & & 1.4314 & $* * *$ & 1.2899 & $* * *$ & 1.5034 & $* * *$ \\
\hline$\alpha_{4}$ & & 2.9005 & $* * *$ & 2.6185 & $* * *$ & 3.0294 & $* * *$ \\
\hline \multicolumn{8}{|c|}{ Mean parameters } \\
\hline \multirow[t]{3}{*}{$\triangle M Q$} & 1 & -0.1357 & $* * *$ & -0.1373 & $* * *$ & -0.0591 & *** \\
\hline & 2 & -0.1612 & $* * *$ & -0.1260 & *** & -0.2374 & $* * *$ \\
\hline & 3 & -0.0259 & & -0.0214 & & -0.0097 & \\
\hline \multirow[t]{3}{*}{ Agg. $\triangle M Q$} & 1 & -0.0075 & & -0.0021 & & -0.0318 & \\
\hline & 2 & 0.0017 & & 0.0036 & & 0.0031 & \\
\hline & 3 & -0.0035 & & -0.0054 & & 0.0095 & \\
\hline \multirow[t]{5}{*}{ Bounce } & 1 & 0.8602 & $* * *$ & 0.7783 & $* * *$ & 0.8736 & *** \\
\hline & 2 & 0.6269 & $* * *$ & 0.5699 & $* * *$ & 0.6202 & $* * *$ \\
\hline & 3 & 0.3621 & $* * *$ & 0.3322 & $* * *$ & 0.2997 & *** \\
\hline & 4 & 0.1967 & $* * *$ & 0.1930 & $* * *$ & 0.0675 & \\
\hline & 5 & 0.0982 & $* * *$ & 0.0922 & $* * *$ & 0.0726 & \\
\hline \multirow[t]{5}{*}{ RptAsk } & 1 & 0.6915 & $* * *$ & 0.6324 & $* * *$ & 0.6505 & *** \\
\hline & 2 & 0.3734 & $* * *$ & 0.3288 & $* * *$ & 0.4557 & $* * *$ \\
\hline & 3 & 0.2515 & $* * *$ & 0.2136 & $* * *$ & 0.3513 & $* * *$ \\
\hline & 4 & 0.0808 & $* * *$ & 0.0626 & $* * *$ & 0.1306 & $* * *$ \\
\hline & 5 & 0.0965 & $* * *$ & 0.0997 & *** & -0.0016 & \\
\hline \multirow[t]{3}{*}{ TrdDif } & 1 & -0.0065 & & -0.0067 & & -0.0051 & \\
\hline & 2 & -0.0027 & & -0.0028 & & -0.0023 & \\
\hline & 3 & -0.0006 & & -0.0010 & & -0.0001 & \\
\hline \multicolumn{8}{|c|}{ Variance parameters } \\
\hline \multirow[t]{4}{*}{$|\Delta M Q|$} & 1 & 0.0317 & $* *$ & 0.0110 & & 0.0621 & * \\
\hline & 2 & 0.0522 & $* * *$ & 0.0232 & & 0.1281 & $* * *$ \\
\hline & 3 & 0.0699 & $* * *$ & 0.0490 & $* * *$ & 0.1091 & $* * *$ \\
\hline & 4 & 0.0647 & $* * *$ & 0.0348 & $* *$ & 0.1248 & $* * *$ \\
\hline \multirow[t]{4}{*}{ Agg. $|\Delta M Q|$} & 0 & 0.0068 & $*$ & -0.0031 & & 0.0170 & ** \\
\hline & 1 & -0.0024 & & -0.0193 & *** & 0.0088 & \\
\hline & 2 & -0.0047 & & -0.0159 & $* * *$ & -0.0020 & \\
\hline & 3 & -0.0041 & & -0.0118 & $* *$ & 0.0016 & \\
\hline
\end{tabular}




\begin{tabular}{|c|c|c|c|c|c|c|c|}
\hline & 4 & -0.0054 & & -0.0085 & & -0.0029 & \\
\hline & 5 & -0.0087 & $* *$ & -0.0100 & $* *$ & -0.0083 & \\
\hline \multirow[t]{3}{*}{$\Delta t$} & 1 & -0.0417 & $* * *$ & -0.0393 & $* * *$ & -0.0443 & \\
\hline & 2 & 0.0012 & & -0.0073 & & 0.0306 & \\
\hline & 3 & 0.0110 & & 0.0012 & & 0.0255 & \\
\hline \multirow[t]{6}{*}{$\overline{\Delta t}$} & 1 & -0.0905 & $* *$ & -0.0792 & $* *$ & -0.2294 & ** \\
\hline & 2 & 0.0082 & & -0.0146 & & -0.0229 & \\
\hline & 3 & -0.0074 & & -0.0196 & & 0.0690 & \\
\hline & 4 & -0.0913 & $* * *$ & -0.0786 & $* *$ & -0.1197 & \\
\hline & 5 & 0.0045 & & 0.0245 & & -0.1017 & \\
\hline & 6 & -0.0246 & & -0.0222 & & 0.0304 & \\
\hline \multirow[t]{4}{*}{ Spread } & 1 & 0.2986 & $* * *$ & 0.2663 & $* * *$ & 0.3801 & $* * *$ \\
\hline & 2 & 0.1526 & $* * *$ & 0.1376 & $* * *$ & 0.2057 & $* * *$ \\
\hline & 3 & 0.0354 & $* * *$ & 0.0146 & & 0.0935 & $* * *$ \\
\hline & 4 & 0.0099 & & -0.0081 & & 0.0760 & $* * *$ \\
\hline \multicolumn{8}{|c|}{ Time dummies in variance specification } \\
\hline 10:00-11:00 & & -0.0308 & * & -0.0147 & & -0.0788 & * \\
\hline 11:00-12:00 & & -0.0399 & ** & -0.0239 & & -0.0721 & * \\
\hline 12:00-13:00 & & 0.0191 & & 0.0221 & & -0.0080 & \\
\hline 13:00-14:00 & & 0.1629 & $* * *$ & 0.1187 & $* * *$ & 0.2539 & $* * *$ \\
\hline 14:00-15:00 & & 0.0701 & $* * *$ & 0.0710 & $* * *$ & 0.1079 & ** \\
\hline 15:00-16:00 & & 0.0058 & & 0.0277 & & -0.0692 & * \\
\hline $16: 00-17: 00$ & & 0.0487 & $* * *$ & 0.0953 & $* * *$ & -0.0157 & \\
\hline
\end{tabular}


Table 7: Tests on the validity of minimum distance functions for the samples A, B, and $\mathrm{C}$ based on the $\xi_{1}$ statistic.

\begin{tabular}{llrrr}
\hline Sample & & $\xi_{1}$ & D.F. & p-value \\
\hline A & Total (August 1995) & 1576.12 & 1092 & 0.0000 \\
B & August, excl. 4. and 22.-24. & 946.82 & 884 & 0.0699 \\
C & Only 4. and 22.-24. & 348.03 & 156 & 0.0000 \\
\hline
\end{tabular}


Table 8: Volatility ratios for the samples A, B, and C. Minimum distance $\xi_{3}$ statistics for all days in the total sample. A volatility ratio which is on a $10 \%, 5 \%$, or $1 \%$ significance level different from one is indicated by $*, * *$, and $* * *$.

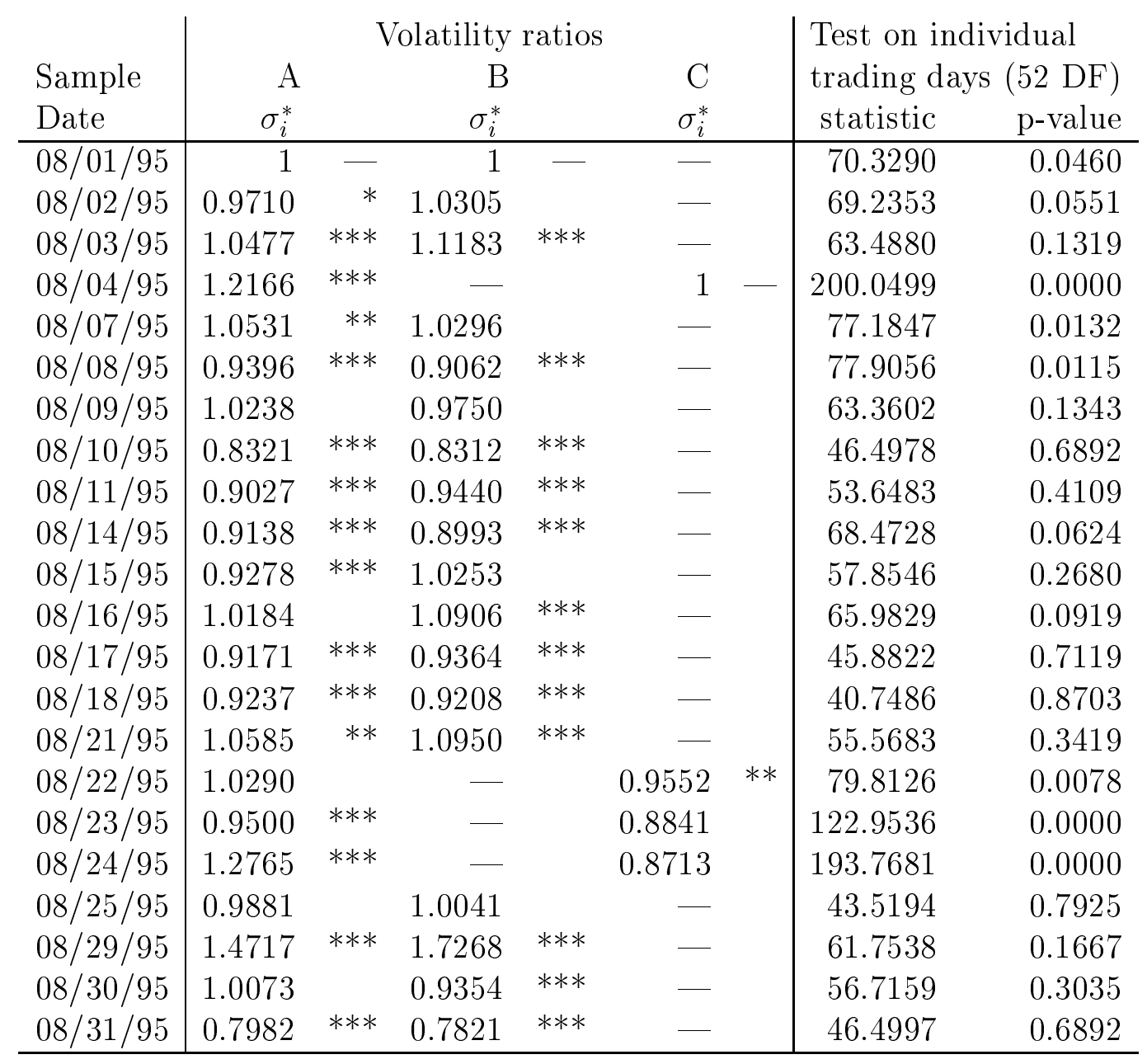


Figure 1: Volatility ratios from the minimum distance estimation step and volatility constants from a GARCH(1,1) model estimated on 5 minute aggregates, standardized on the first day.

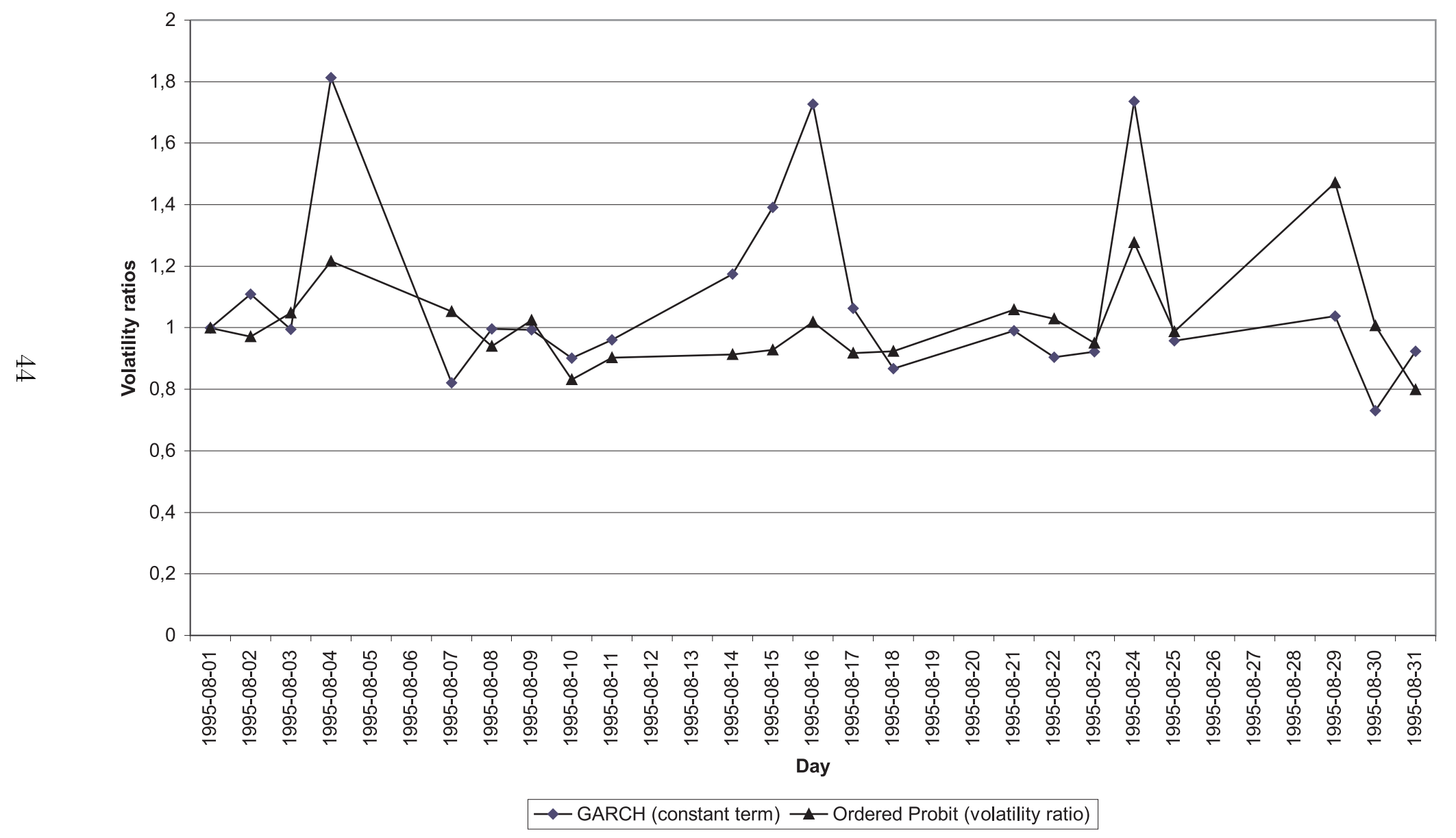

